\title{
Optimal waist circumference cutoff values to predict cardiometabolic alterations in a Venezuela national representative sample. The EVESCAM study
}

\author{
Valores óptimos de punto de corte de circunferencia abdominal para predecir \\ alteraciones cardiometabólicas en una muestra representativa nacional de Venezuela. \\ El estudio EVESCAM
}

Juan P. González-Rivas ${ }^{1,2,3 *}$, Jeffrey I. Mechanick, Rocio Iglesias-Fortes ${ }^{3}$, Diana De-Oliveira-Gomes ${ }^{3}$, Jesús Silva ${ }^{3}$, José Valencia ${ }^{3}$, Estherbany Figueroa ${ }^{3}$, Maritza Duran $^{3}$, Eunice Ugeß ${ }^{3,5}$, María M. Infante-García ${ }^{3}$, María Inés Marulanda ${ }^{3}$, and Ramfis Nieto-Martínez $z^{2,3,6,7}$

'International Clinical Research Center, St Anne's University Hospital Brno, Brno, Czech Republic; '2Department of Global Health and Population. Harvard TH Chan School of Public Health, Harvard University, Boston, Massachusetts, USA; ${ }^{3}$ Foundation for Clinic, Public Health, and Epidemiological Research of Venezuela (FISPEVEN), Caracas, Venezuela; ${ }^{4}$ Divisions of Cardiology and Endocrinology, Diabetes and Bone Disease, Icahn School of Medicine at Mount Sinai, New York, New York, USA; ${ }^{5}$ Department of Social and Preventive Medicine, Public Health Research Unit, School of Medicine, Universidad Centro-Occidental "Lisandro Alvarado", Barquisimeto, Venezuela; 'LifeDoc Diabetes and Obesity Clinic, Memphis, TN, US; ${ }^{7}$ Department of Physiology, School of Medicine, University Centro-Occidental "Lisandro Alvarado" and Cardio-metabolic Unit 7, Barquisimeto, Venezuela

\begin{abstract}
Objective: Waist circumference (WC) value reflects abdominal adiposity, but the amount abdominal fat that is associated to cardiometabolic risk factors varies among ethnicities. Determination of metabolic abnormalities has not undergone a WC adaptation process in Venezuela. The aim of the study was (1) to determine the optimal WC cutoff value associated with $\geq 2$ cardiometabolic alterations and (2) incorporating this new WC cutoff, to determine the prevalence of abdominal obesity and cardiometabolic risk factors related in Venezuela. Methods: The study was national population-based, cross-sectional, and randomized sample, from 2014 to 2017. To assess performance of WC for identifying cardiometabolic alterations, receiver operating characteristics curves, area under the curve (AUC), sensitivity, specificity, and positive likelihood ratios were calculated. Results: Three thousand three hundred eighty-seven adults were evaluated with mean age of $41.2 \pm 15.8$ years. Using the best tradeoff between sensitivity and specificity, WC cutoffs of $90 \mathrm{~cm}$ in men (sensitivity $=72.4 \%$ and specificity = $66.1 \%$ ) and $86 \mathrm{~cm}$ in women (sensitivity $=76.2 \%$ and specificity $=61.4 \%$ ) were optimal for aggregation of $\geq 2$ cardiometabolic alterations. AUC was 0.75 in men and 0.73 in women using these new cutoffs. Prevalence of abdominal obesity and metabolic syndrome was 59.6\% (95 Cl; 57.5-61.7) and 47.6\% (95 Cl; 45.2-50.0), respectively. Cardiometabolic risk factors were associated with being men, higher age, adiposity, and living in northern or western regions. Conclusion: The optimal $W C$ values associated with cardiometabolic alterations were $90 \mathrm{~cm}$ in men and $86 \mathrm{~cm}$ in women. More than half of the Venezuelan population had abdominal obesity incorporating this new WC cutoff.
\end{abstract}

Key words: Abdominal obesity. Adiposity. Metabolic syndrome. Venezuela. Waist circumference

Correspondence:

Juan P. González-Rivas

E-mail: juan.gonzalez@fnusa.cz
Available online: $23-12-2020$ Arch Cardiol Mex (Eng). 2021;91(3):240-248 www.archivoscardiologia.com 2604-7063 / @ 2020 Instituto Nacional de Cardiología Ignacio Chávez. Published by Permanyer. This is an open access article under the CC BY-NC-ND license (http://creativecommons.org/licenses/by-nc-nd/4.0/). 


\section{Resumen}

Objetivo: El valor de la circunferencia abdominal (CA) refleja la adiposidad abdominal, pero la cantidad de grasa abdominal asociada a factores de riesgo cardiometabólicos varía según la etnia. La determinación de anomalías metabólicas no se ha adaptado a la CA en Venezuela. 1) Detrerminar el valor de corte óptimo de CA asociados a $\geq 2$ alteraciones cardiometabólicas. 2) Incorporando este nuevo límite de CA, determinar la prevalencia de obesidad abdominal y factores de riesgo cardiometabólicos relacionados en Venezuela. Métodos: Fue un estudio poblacional, transversal, de muestreo aleatorio de 2014 a 2017. Para evaluar el valor de CA para identificar alteraciones cardiometabólicas, se realizaron curvas características operativa del receptor y se calculó área bajo la curva $(A B C)$, sensibilidad, especificidad y razón de similitud. Resultados: se evaluaron 3387 adultos con una edad promedio de $41.2 \pm 15.8$ años. Utilizando la mejor relación entre sensibilidad y especificidad, se determinó que los valores de corte de $90 \mathrm{~cm}$ en hombres (sensibilidad $=72.4 \%$ y especificidad $=66.1 \%$ ) y 86 $\mathrm{cm}$ en mujeres (sensibilidad $=76.2 \%$ y especificidad $=61.4 \%$ ) fueron óptimos para la agregación de $\geq 2$ alteraciones cardiometabólicas. EI ABC fue de 0,75 en hombres y de 0,73 en mujeres usando estos nuevos puntos de corte. La prevalencia de obesidad abdominal y síndrome metabólico fue 59.6\% (95IC; 57.5 - 61.7) y 47.6\% (95Cl; 45.2 - 50.0), respectivamente. La presencia de factores de riesgo cardiometabólicos se asoció con ser hombre, mayor edad, adiposidad y vivir en regiones del norte o del oeste. Conclusión: Los valores óptimos de CA asociados con alteraciones cardiometabólicas fueron $90 \mathrm{~cm}$ en hombres y $86 \mathrm{~cm}$ en mujeres. Más de la mitad de la población venezolana tenía obesidad abdominal al incorporar este nuevo corte de $C A$.

Palabras clave: Obesidad abdominal. Adiposidad. Síndrome metabólico. Venezuela. Circunferencia abdominal

\section{Introduction}

Cardiovascular disease (CVD) was responsible for $31.8 \%$ of all deaths in Venezuela in 2017 and has increased by $10.8 \%$ in the past decade ${ }^{1}$ prompting an urgent call for action to implement population-based preventive strategies. Regional adaptation of diagnostic criteria and tools is a mandatory step to implement tailored interventions to reduce CVD burden. For example, using all available data from Asian countries, the World Health Organization recommends lowering body mass index (BMI) cut-points to $23-27.5 \mathrm{~kg} / \mathrm{m}^{2}$ as overweight and $\mathrm{BMI} \geq 27.5 \mathrm{~kg} / \mathrm{m}^{2}$ as obese, to promote early public health action for Asians ${ }^{2}$. Complications related to Adiposity-Based Chronic Disease (ABCD) ${ }^{3}$ are the major modifiable risk factors that underlie CVD, increasing the risk for hypertension, insulin resistance (or Stage 1 dysglycemia-based chronic disease $[\mathrm{DBCD}]^{4}$, and dyslipidemia, which can be viewed as a cluster known as metabolic syndrome (MetS) ${ }^{5}$. MetS also involves various residual risk factors, such as inflammation, atherogenesis, and platelet hyper-reactivity (prothrombotic state), which independently or together increase the risk for coronary artery disease ${ }^{6}$, stroke, type 2 diabetes (T2D) ${ }^{7}$, and cancer ${ }^{5,8}$.

To estimate the prevalence of MetS and abdominal obesity, the International Diabetes Federation (IDF) recommends adapting waist circumference (WC) cutoffs in different ethnic groups. For Latin American, the IDF recommends applying the values of South Asian countries $(90 \mathrm{~cm}$ for men and $80 \mathrm{~cm}$ for women) until more data are available ${ }^{9}$. Due to a paucity of cohort studies in Latin America to potentially adapt WC cutoff values associated with the development of CVD events, a variety of strategies have been enlisted. One of the most frequently used strategy is to determine the correlations of different WC cutoffs with individual cardiometabolic components. For example, in 14,893 adults between 35 and 74 years from six cities in Brazil, the optimal WC cutoffs correlating with $\geq 2$ MetS components were $92.0 \mathrm{~cm}$ in men and $86.6 \mathrm{~cm}$ in women ${ }^{10}$. In 318 adults older than 18 years from Cuenca city, Ecuador, the optimal WC cutoffs correlating with $\geq 2$ MetS components were $95.5 \mathrm{~cm}$ in men and 91.5 $\mathrm{cm}$ in women ${ }^{11}$. In 1902 adults with a mean of age 38.7 from Maracaibo city, Venezuela, the optimal WC cutoff correlating with $\geq 2$ MetS components were $95.1 \mathrm{~cm}$ in men and $90.2 \mathrm{~cm}$ in women ${ }^{12}$. Finally, in 362 adults from San Cristobal, Venezuela, the optimal WC cutoff correlating with $\geq 2$ MetS components was $95.2 \mathrm{~cm}$ in men and $88.7 \mathrm{~cm}$ in women ${ }^{13}$. Alternatively, The Latin American Group for the Study of MetS (GLESMO), analyzing data from México, El Salvador, Venezuela, Colombia, and Paraguay, used a different methodology based on the best value to detect $100 \mathrm{~cm}^{3}$ of intraabdominal fat at the $4^{\text {th }}$ and $5^{\text {th }}$ lumbar vertebrae using computer tomography images and recommended a cutoff value of $94 \mathrm{~cm}$ in men and $90 \mathrm{~cm}$ in women ${ }^{14}$.

Despite the efforts of these studies, they do not have a national representativity, limiting extrapolation to an entire population. In addition, defining abdominal obesity using only a surrogate of the amount of fat can fail to detect the 
specific level of adiposity associated with the presence of cardiometabolic risk factors. This is particularly relevant in Latin American populations, where cardiometabolic risk factors remain demonstrable with low amounts of adipose tissue $^{15}$. Based on these knowledge gaps, the Venezuelan Study of Cardiometabolic Health (EVESCAM, for its acronym in Spanish) database, which includes a national representative evaluation of adults of the eight regions of the country, was interrogated. The aims of this paper were (1) to determine the optimal WC cutoff value associated with $\geq 2$ cardiometabolic alterations; (2) Incorporating this new WC cutoff as part of the diagnostic criteria to determine the prevalence of abdominal obesity and cardiometabolic risk factors related in Venezuela

\section{Methods}

\section{Study design}

The study design, sampling protocol, and implementation strategies were described previously ${ }^{16,17}$. In brief, the EVESCAM was a population-based, observational, cross-sectional, and cluster sampling study designed to evaluate cardiometabolic risk factors among subjects aged $\geq 20$ years in Venezuela from July 2014 to January 2017 .

\section{Population}

A multi-stage stratified sampling method was used to select a representative sample of the general population of Venezuela. Four thousand four hundred fifty-four women and men, aged 20 years and older, were recruited from randomly selected samples in the eight regions of Venezuela. Initially, 23 cities from the eight regions - one to four cities per region - were chosen. Each selected city was stratified by municipalities. Two municipalities in each city, then two parishes in each municipality, and finally, two locations in each parish were randomly selected. Further mapping and census-taking for each location identified the streets or blocks and selected the households that were eventually visited. Inclusion criteria were subjects, 20 years or older, living in the house selected for more than 6 months. Exclusion criteria were current pregnancy, inability to stand or communicate, or refusal to participate in the study by not signing the informed consent.

The target sample size was calculated based on a previous report on diabetes (prevalence $7.7 \%$, standard deviation $1.55 \%$, and confidence level $95 \%)^{18}$ and found to be 2940 . Therefore, considering a minimal expected response rate of $70 \%$, the final target sample size was 4200 , representing the proportions of the country in terms of age, sex, and proportion of regions. For this study, 4454 subjects were recruited $(86.3 \%$ urban and $13.7 \%$ rural areas), among which 3,420 were evaluated, corresponding to a net response rate of $77.3 \%$.

The study protocol complied with the Helsinki declaration and approved by the National Bioethics Committee (CENABI). Consent from all participants was obtained and filed. The present report is presented according to the Strengthening the Reporting of Observational Studies in Epidemiology (STROBE) ${ }^{19}$.

\section{Clinical and biochemical measures}

A customized questionnaire was used to collect information on demographics, family and personal history, T2D and cardiovascular risk, and socioeconomic status (SES). Questionnaires, anthropometrics, and other physical measurements were obtained by trained and certified health personnel. Blood pressure was measured twice, with 5 min intervals, in the right arm, supported at heart level, in a sitting position, after $5 \mathrm{~min}$ of rest, with a validated oscillometric sphygmomanometer (Omron HEM-705C Pint ${ }^{\circledR}$ Omron Healthcare CO., Kyoto/ Japan ${ }^{20}$. Weight was measured with the lightest possible clothes, without shoes, using a calibrated scale (Tanita UM-081 ${ }^{\circledR}$, Japan). Height was measured using a portable stadiometer (Seca $206^{\circledR}$ Seca GmbH \& Co., Hamburg, Germany). BMl $=\mathrm{kg} / \mathrm{m}^{2}$ was calculated for all subjects. WC was measured twice with a metric tape, at the iliac crest, in a horizontal plane with the floor, at the end of expiration, and the average of both was used.

Blood specimens were collected according to a standardized protocol after at least 8-h of fasting. Samples were centrifuged, frozen, and shipped to the central laboratory to be stored at $-40^{\circ}$ until assay. Blood tests included fasting blood glucose and lipid profile.

\section{Definition of variables}

To detect the cardiometabolic components associated with abdominal obesity was used the MetS criteria of the Joint Interim Statement: high triglycerides $\geq 150 \mathrm{mg} / \mathrm{dL}$; low high-density lipoprotein cholesterol (HDL-c) $<40 \mathrm{mg} / \mathrm{dL}$ in men or $<50 \mathrm{mg} / \mathrm{dL}$ in women; high blood pressure $\geq 130 / 85 \mathrm{mmHg}$ or use of antihypertensive treatment; and high blood glucose $\geq 100 \mathrm{mg} / \mathrm{dL}$ or self-report of diabetes. ${ }^{21}$

Abdominal obesity was determined as the WC value associated with $\geq 2$ MetS components described above. 
The nutritional state was categorized according to the BMl as underweight $<18.5 \mathrm{~kg} / \mathrm{m}^{2}$, normal weight 18.5 $24.9 \mathrm{~kg} / \mathrm{m}^{2}$, overweight $25-29.9 \mathrm{~kg} / \mathrm{m}^{2}$, and obesity $\geq 30 \mathrm{~kg} / \mathrm{m}^{2}$. A questionnaire, validated in the Venezuelan population and based on four variables (source of income, profession of householder, educational level, and housing conditions), was used to determine SES. Thus, the population was categorized by 5 strata: SES I - II high-middle-high; SES III - middle; SES IV - poor; and SES V - extreme poverty or extremely poor ${ }^{22}$.

\section{Data analysis}

All calculations were performed using SPSS 20 software (IBM corp. Released 2011; Armonk, NY, USA). Data were weighted to address any imbalance in the distribution of sociodemographic factors in the sample, compared with the whole Venezuelan population. Sampling weights were created using standardized population weights for gender in combination with a second set of weights based on the region/age distribution in Venezuela. Population distributions were obtained from the Venezuelan 2011 census. All continuous variables were initially tested for normality $(\mathrm{Q}-\mathrm{Q}$ plot and Kolmogorov-Smirnov test) and presented as mean \pm standard deviation (SD). Differences between means were assessed by the Student's t-test. Qualitative variables were presented as prevalence and $95 \%$ confidence intervals $(95 \% \mathrm{Cl})$ and compared using the Chi-square test. To assess performance of WC for identifying cardiovascular risk, receiver operating characteristics curves, area under the curve (AUC), sensitivity, specificity, and positive likelihood ratios were calculated. The highest sum sensitivity plus specificity favoring sensitivity (when each value was $>50 \%$ ) was used to determine the optimal cutoff value to detect abnormalities. Logistic regressions were made adjusting by age and gender to assess the risk and social factors related to the MetS and its components. $p<0.05$ was considered statistically significant.

\section{Results}

\section{Subject characteristics}

Out of 3454 subjects who completed all stages of data collection, 34 did not complete the evaluation, and 33 had missing data on one or more variables needed. The final sample comprised 3387 participants (Fig. 1). Mean age was $41.2 \pm 15.8$ years, higher in men than women $(p=0.008)$ (Table 1$)$. Men showed a worse

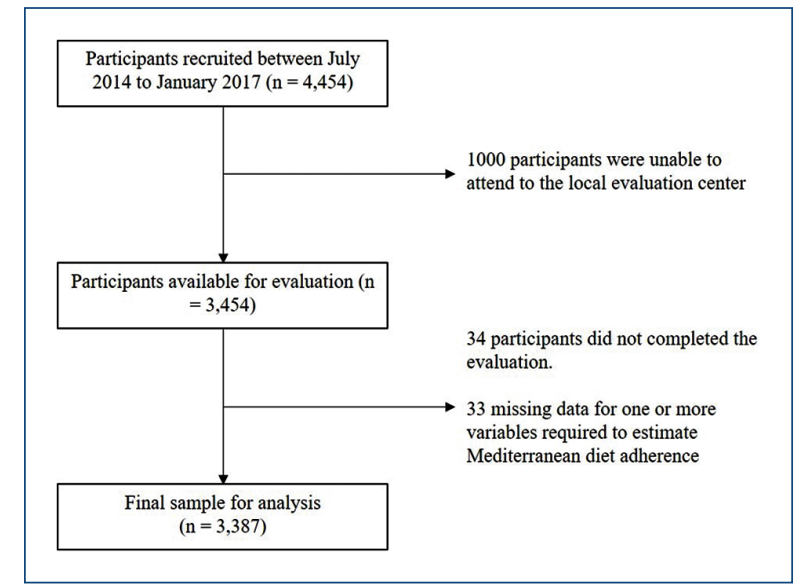

Figure 1. Final sample for analysis to estimate the metabolic syndrome prevalence.

cardiometabolic profile than women, with higher values of blood pressure, WC, triglycerides, blood glucose, and lower value of HDL-c than women $(p<0.01)$, despite having a similar BMI. A $39.1 \%$ of the population had a university degree and this was higher in women than men $(p=0.002)$. Almost half of the population was poor and extremely poor SES and $80 \%$ were from urban areas.

\section{Optimal WC}

To determine the WC associated with $\geq 2$ cardiometabolic alterations, the AUC was $0.75(95 \% \mathrm{Cl}$; 0.73$0.78)$ in men and $0.73(95 \% \mathrm{Cl} ; 0.71-0.76)$ in women (Fig. 2), corresponding to a probability around $74 \%$ to detect subjects with $\geq 2$ alterations. Using the best tradeoff between sensitivity and specificity, a cutoff value of $90 \mathrm{~cm}$ in men (sensitivity $=72.4 \%$ and specificity $=66.1 \%$ ) and $86 \mathrm{~cm}$ in women (sensitivity $=76.2 \%$ and specificity $=61.4 \%$ ) were optimal for aggregation of $\geq 2$ alternations in Venezuelan adults (Table 2).

\section{Prevalence of abdominal obesity and cardiometabolic risk factors}

With these cutoff values, the prevalence of abdominal obesity in Venezuela was 59.6\% (95\% Cl; $57.5-61.7)$, similar between genders. Incorporating this new WC cutoff as part of the diagnostic criteria, the prevalence of MetS was $47.6 \%$ (95 Cl; 45.2-50.0), higher in men (50.0\% [95 Cl; 47.7-52.3) than in women (45.4\% [95 Cl; 42.9-47.8) $(p=0.007)$ (Table 3). Low HDL-c was the most prevalent alteration (78\%), followed by abdominal 
Table 1. Characteristics of the subjects

\begin{tabular}{|c|c|c|c|c|}
\hline Variable & Men & Women & Total & $\mathbf{p}$ \\
\hline n $(\%)$ & $1617(47.7)$ & $1770(52.3)$ & 3387 & \\
\hline Age (years) & $41.9 \pm 16.5$ & $40.5 \pm 15.1$ & $41.2 \pm 15.8$ & 0.008 \\
\hline Systolic BP (mmHg) & $130.5 \pm 19.3$ & $123.1 \pm 19.3$ & $126.6 \pm 20.7$ & $<0.001$ \\
\hline Diastolic BP (mmHg) & $75.7 \pm 11.6$ & $74.7 \pm 11.4$ & $75.2 \pm 11.5$ & 0.008 \\
\hline BMI & $26.7 \pm 5.4$ & $27.0 \pm 6.3$ & $26.8 \pm 5.9$ & 0.114 \\
\hline Waist circumference $(\mathrm{cm})$ & $92.9 \pm 14.0$ & $90.4 \pm 14.0$ & $91.6 \pm 14.1$ & $<0.001$ \\
\hline Triglycerides (mg/dL) & $116.7 \pm 72.7$ & $100.6 \pm 54.3$ & $108.3 \pm 64.3$ & $<0.001$ \\
\hline HDL-c (mg/dL) & $34.9 \pm 10.4$ & $38.7 \pm 11.2$ & $36.9 \pm 11.0$ & $<0.001$ \\
\hline Blood glucose (mg/dL) & $105.2 \pm 33.5$ & $99.3 \pm 26.2$ & $102.1 \pm 30.1$ & $<0.001$ \\
\hline $\begin{array}{l}\text { Academic degree (\%) } \\
\text { Primary } \\
\text { Secondary } \\
\text { University }\end{array}$ & $\begin{array}{l}19.0(15.2-18.8) \\
45.2(42.8-47.6) \\
35.8(33.5-38.1)\end{array}$ & $\begin{array}{l}18.1(15.0-18.4) \\
39.8(37.5-42.1) \\
42.2(39.9-44.5)\end{array}$ & $\begin{array}{l}18.5(15.3-17.8) \\
42.4(40.7-44.1) \\
39.1(37.5-40.7)\end{array}$ & 0.001 \\
\hline $\begin{array}{l}\text { Social economic stratus (\%) } \\
\text { V - Extremely poor } \\
\text { IV - Poor } \\
\text { III - Middle } \\
\text { I-II - High/Middle-High }\end{array}$ & $\begin{array}{c}6.3(5.1-7.3) \\
40.7(38.3-43.1) \\
30.8(28.6-33.1) \\
22.3(20.2-24.3)\end{array}$ & $\begin{array}{c}5.1(4.1-6.1) \\
43.3(41.0-45.6) \\
31.4(29.2-33.6) \\
20.2(18.3-22.0)\end{array}$ & $\begin{array}{c}5.7(5.0-6.5) \\
42.0(40.3-43.7) \\
31.1(29.5-32.7) \\
21.2(19.8-22.5)\end{array}$ & 0.152 \\
\hline $\begin{array}{l}\text { Location (\%) } \\
\text { Urban } \\
\text { Rural }\end{array}$ & $\begin{array}{l}82.3(80.4-84.2) \\
17.7(15.8-19.6)\end{array}$ & $\begin{array}{l}79.3(77.4-81.2) \\
20.7(18.8-22.6)\end{array}$ & $\begin{array}{l}80.8(79.5-82.1) \\
19.2(17.9-20.5)\end{array}$ & 0.029 \\
\hline
\end{tabular}

Data are presented as mean \pm SD. Proportions are presented as percent and 95\% Cl. BP: blood pressure; HDL-c: high-density lipoprotein cholesterol

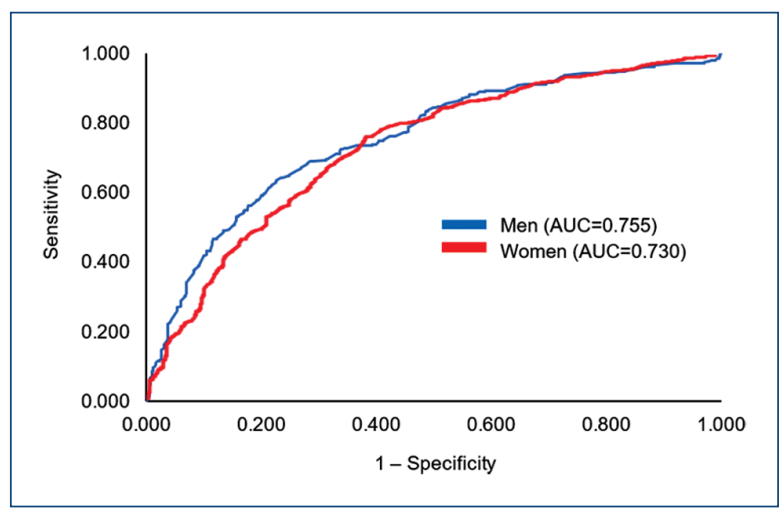

Figure 2. Receiver operating characteristic curves constructed to determine waist circumference cutoff points for the detection of multiple risk factor aggregations in the general population by gender.

obesity (59.6\%), high blood glucose (43.6\%), and high blood pressure (39.6\%). Men presented a higher prevalence of high blood pressure, blood glucose, and triglycerides, but a lower prevalence of low HDL-c than women $(p<0.01)$. All cardiometabolic risk factors, except low HDL, increased with age $(p<0.001)$. In the group with 70 years or older, the prevalence of MetS was $72.3 \%$, driven by a very high prevalence of high blood pressure in this age group (79.6\%).

Independent of age and gender, the prevalence of MetS and all its components increased with the presence of overweight and obesity. Compared with normal-weight subjects, the OR related to MetS was 7.2 $(95 \% \mathrm{Cl} ; 5.9-8.9)$ in those with overweight and 20.4 $(95 \% \mathrm{Cl} ; 16.1-26.0)$ in those with obesity. The MetS components in subjects with overweight ranged from $\mathrm{OR}=1.7(95 \% \mathrm{Cl} ; 1.4-2.0)$ for high blood glucose to 19.3 (95\% Cl; 15.5-24.0) for abdominal obesity; in those with obesity ranged from $\mathrm{OR}=2.2(95 \% \mathrm{Cl} ; 1.9-2.7)$ to $\mathrm{OR}=382.3(95 \% \mathrm{Cl}$; 199.6-731.9), respectively. Subjects in the lowest SES had a lower risk for abdominal obesity than higher SES (Table 4), the rest of cardiometabolic risk factors were not related to academic degree, SES, or location rural/urban.

The prevalence of cardiometabolic risk factors was different among diverse regions of the country. The 
Table 2. Sensitivity, specificity, sum, and likelihood ratio of abdominal circumference cutoff point

\begin{tabular}{|l|c|c|c|c|c|c|c|c|c|}
\hline Men & \multicolumn{5}{|c|}{ Women } \\
\hline Cut point & Sensitivity & Specificity & Sum & +LR & Cut point & Sensitivity & Specificity & Sum & +LR \\
\hline 86 & 81.5 & 52.4 & 1.339 & 1.71 & 82 & 85.9 & 44.7 & 1.306 & 1.55 \\
\hline 87 & 78.8 & 54.3 & 1.331 & 1.72 & 83 & 84.5 & 48.3 & 1.328 & 1.63 \\
\hline 88 & 76.2 & 56.7 & 1.329 & 1.76 & 84 & 81.0 & 51.8 & 1.329 & 1.68 \\
\hline 89 & 73.8 & 60.1 & 1.339 & 1.84 & 85 & 79.4 & 56.9 & 1.363 & 1.84 \\
\hline 90 & 72.4 & 66.1 & 1.385 & 2.13 & 86 & 76.2 & 61.4 & 1.376 & 1.97 \\
\hline 91 & 69.5 & 68.5 & 1.380 & 2.20 & 87 & 72.4 & 63.1 & 1.354 & 1.95 \\
\hline 92 & 67.3 & 73.0 & 1.403 & 2.49 & 88 & 70.4 & 65.6 & 1.360 & 2.04 \\
\hline 93 & 65.0 & 75.2 & 1.402 & 2.62 & 89 & 66.9 & 68.5 & 1.355 & 2.12 \\
\hline 94 & 62.0 & 78.3 & 1.403 & 2.85 & 90 & 63.7 & 70.4 & 1.342 & 2.15 \\
\hline
\end{tabular}

+LR: likelihood ratios.

Table 3. Prevalence of cardiometabolic risk factors

\begin{tabular}{|c|c|c|c|c|c|c|}
\hline Variables & MetS & High blood pressure & High triglycerides & Abdominal obesity & Low HDL-c & High blood glucose \\
\hline Total & $47.6(45.2-50.0)$ & $39.6(37.0-42.2)$ & $22.7(19.7-25.7)$ & $59.6(57.5-61.7)$ & $78.0(76.4-79.6)$ & $43.6(41.1-46.1)$ \\
\hline Men & $50.0(47.7-52.3)$ & $44.5(41.8-47.2)$ & $24.7(21.7-27.8)$ & $59.1(56.7-61.5)$ & $71.2(69.5-72.9)$ & $49.4(46.9-52.0)$ \\
\hline Women & $45.4(43.0-47.8)$ & $35.0(32.5-37.6)$ & $20.9(18.0-23.8)$ & $60.0(57.7-62.3)$ & $84.3(82.9-85.7)$ & $38.3(35.8-40.8)$ \\
\hline$p$ & 0.007 & $<0.001$ & 0.008 & 0.612 & $<0.001$ & $<0.001$ \\
\hline $\begin{array}{l}\text { Age } \\
20-44 \\
45-69 \\
\geq 9 . \\
\text { p }\end{array}$ & $\begin{array}{c}35.7(33.4-38.0) \\
65.8(63.5-68.1) \\
72.3(70.1-74.5) \\
<0.001\end{array}$ & $\begin{array}{c}24.3(22.0-26.6) \\
61.1(58.5-63.7) \\
79.6(77.4-81.8) \\
<0.001\end{array}$ & $\begin{array}{c}15.7(13.1-18.3) \\
33.3(30.0-36.6) \\
37.4(34.0-40.9) \\
<0.001\end{array}$ & $\begin{array}{c}51.8(49.6-54.0) \\
72.8(70.9-74.8) \\
68.0(66.0-70.0) \\
<0.001\end{array}$ & $\begin{array}{c}80.5(79.0-82.0) \\
74.7(73.0-76.4) \\
70.9(69.1-72.6) \\
<0.001\end{array}$ & $\begin{array}{c}34.8(32.4-37.2) \\
56.6(54.0-59.1) \\
63.1(60.6-65.6) \\
<0.001\end{array}$ \\
\hline
\end{tabular}

Proportions are presented as percent and 95\% Cl. Abbreviations: HDL-c: high-density lipoprotein cholesterol; MetS: metabolic syndrome.

prevalence of MetS was higher in the regions located at northern and western of Venezuela (Fig. 3), driven by high prevalence rates associated with abdominal obesity, low HDL-c, and high blood glucose $(p<0.001)$. In the central region, the prevalence of low HDL-c was 95.3\%, whereas in Los Llanos (Plains), located in the middle on the country, presented the lowest prevalence of MetS, related to the lowest prevalence of high blood pressure and triglycerides, the second-lowest prevalence of low HDL-c, abdominal obesity, and high blood glucose $(p<0.001)$.

\section{Discussion}

Waist circumference cutoff values of $90 \mathrm{~cm}$ for men (sensitivity $=72.4 \%$ and specificity $=66.1 \%$ ) and $86 \mathrm{~cm}$ for women (sensitivity $=76.2 \%$ and specificity $=61.4 \%$ ) were optimal for the detection of cardiometabolic risk factor aggregation. Using these cutoffs, the prevalence of abdominal obesity was $59.6 \%(95 \% \mathrm{Cl} 57.5-61.7)$, similar between genders. MetS prevalence was $47.6 \%$, higher in men than women, and increased with age (except low HLD-c) and BMI. The prevalence of cardiometabolic risk factors also varied by regions, being higher in those areas located at the northern and western parts of the country and lower at Los Llanos.

Compared with previous studies, including the Venezuelan population, the WC cutoff values in this study based on the EVESCAM registry are the lowest reported at this date. Specifically, in men, the WC value was $90 \mathrm{~cm}$ using EVESCAM data, compared with Maracaibo city of $95.1 \mathrm{~cm}$ (12); San Cristobal city of $95.2 \mathrm{~cm}$ 
Table 4. Risk factors related to cardiometabolic components

\begin{tabular}{|c|c|c|c|c|c|c|}
\hline Variables & MetS & $\begin{array}{l}\text { High blood } \\
\text { pressure }\end{array}$ & $\begin{array}{c}\text { High } \\
\text { triglycerides }\end{array}$ & $\begin{array}{c}\text { Abdominal } \\
\text { obesity }\end{array}$ & Low HDL-c & $\begin{array}{l}\text { High blood } \\
\text { glucose }\end{array}$ \\
\hline $\begin{array}{l}\text { Nutritional status } \\
\text { Normal weight } \\
\text { Low weight } \\
\text { Overweight } \\
\text { Obesity }\end{array}$ & $\begin{array}{c}1 \\
0.2(0.1-0.4) \\
7.2(5.9-8.9) \\
20.4(16.1-26.0)\end{array}$ & $\begin{array}{c}1 \\
0.6(0.4-1.1) \\
3.0(2.4-3.6) \\
4.7(3.8-5.8)\end{array}$ & $\begin{array}{c}1 \\
0.2(0.1-0.5) \\
1.8(1.5-2.3) \\
3.0(2.4-3.8)\end{array}$ & $\begin{array}{c}1 \\
0.0(0.0-0.2) \\
19.3(15.5-24.0) \\
382.3(199.6-731.9)\end{array}$ & $\begin{array}{c}1 \\
0.6(0.4-0.9) \\
1.9(1.5-2.3) \\
3.3(2.6-4.3)\end{array}$ & $\begin{array}{c}1 \\
0.7(0.5-1.0) \\
1.7(1.4-2.0) \\
2.2(1.9-2.7)\end{array}$ \\
\hline $\begin{array}{l}\text { Academic degree } \\
\text { Primary } \\
\text { Secondary } \\
\text { University }\end{array}$ & $\begin{array}{c}1 \\
1.2(0.9-1.5) \\
0.9(0.7-1.2)\end{array}$ & $\begin{array}{c}1 \\
1.1(0.9-1.4) \\
0.9(0.7-1.2)\end{array}$ & $\begin{array}{c}1 \\
0.9(0.7-1.2) \\
1.2(0.9-1.5)\end{array}$ & $\begin{array}{c}1 \\
1.4(1.1-1.7) \\
1.2(0.9-1.4)\end{array}$ & $\begin{array}{c}1 \\
0.7(0.5-0.9) \\
0.5(0.3-0.6)\end{array}$ & $\begin{array}{c}1 \\
0.9(0.7-1.2) \\
0.9(0.8-1.2)\end{array}$ \\
\hline $\begin{array}{l}\text { Social-economic status } \\
\text { V - Extremely poor } \\
\text { IV - Poor } \\
\text { III - Middle } \\
\text { I-II - High/Middle-High }\end{array}$ & $\begin{array}{c}1 \\
1.3(0.9-1.8) \\
1.2(0.8-1.6) \\
1.1(0.8-1.6)\end{array}$ & $\begin{array}{c}1 \\
1.4(1.0-2.0) \\
1.4(1.0-2.0) \\
1.3(0.9-1.9)\end{array}$ & $\begin{array}{c}1 \\
1.0(0.7-1.5) \\
1.1(0.8-1.7) \\
1.2(0.8-1.9)\end{array}$ & $\begin{array}{c}1 \\
1.8(1.3-2.4) \\
1.9(1.4-2.7) \\
1.8(1.3-2.6)\end{array}$ & $\begin{array}{c}1 \\
1.1(0.7-1.6) \\
0.9(0.6-1.3) \\
0.8(0.5-1.1)\end{array}$ & $\begin{array}{c}1 \\
1.2(0.9-1.7) \\
1.4(1.0-1.9) \\
1.0(0.7-1.4)\end{array}$ \\
\hline $\begin{array}{c}\text { Location } \\
\text { Rural } \\
\text { Urban }\end{array}$ & $\begin{array}{c}1 \\
1.1(0.9-1.3)\end{array}$ & $\begin{array}{c}1 \\
1.0(0.9-1.3)\end{array}$ & $\begin{array}{c}1 \\
1.1(0.9-1.4)\end{array}$ & $\begin{array}{c}1 \\
1.0(0.89-1.2)\end{array}$ & $\begin{array}{c}1 \\
0.8(0.6-1)\end{array}$ & $\begin{array}{c}1 \\
1.0(0.8-1.2)\end{array}$ \\
\hline
\end{tabular}

Logistic regression is presented as $\mathrm{OR}$ and $95 \% \mathrm{Cl}$. Abbreviations: HDL-c: high-density lipoprotein cholesterol; MetS: metabolic syndrome.

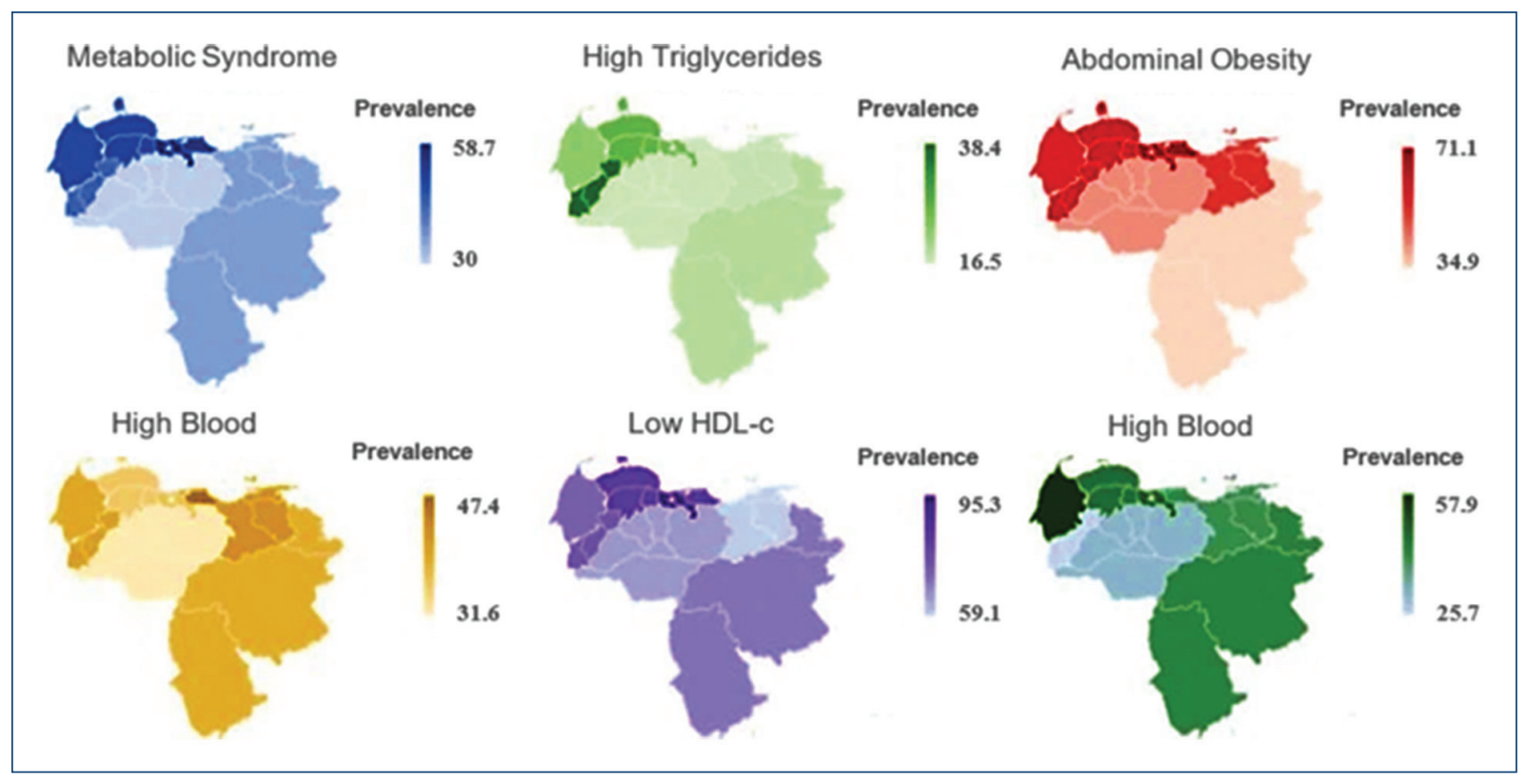

Figure 3. Prevalence of syndrome metabolic and its components by region.

(13); and GLESMO (Mexico, El Salvador, Venezuela, Colombia, and Paraguay) of $94 \mathrm{~cm}$ (14). In women, the figures for EVESCAM are $86 \mathrm{~cm}$, compared with Maracaibo city of $90.2 \mathrm{~cm}(12)$; San Cristobal city of $88.7 \mathrm{~cm}$ (13); and GLESMO of $92 \mathrm{~cm}$ (14). The lower values found in this report are associated with the elevated prevalence of MetS components: low HDL-c (78.0\%) and high blood glucose $(43.6 \%)$, which were $38 \%$ and $80 \%$ higher than the values observed in Maracaibo city (12). Compared with other locations, in men, this value was also lower than the observed in Ecuador $(95.5 \mathrm{~cm})$ (11), Brazil $(92 \mathrm{~cm})(10)$, and Portugal $(93.5 \mathrm{~cm})^{23}$, but 
higher than Japan $(85 \mathrm{~cm})^{24}$ and in eight countries of Sub-Sahara Africa $(81 \mathrm{~cm})^{25}$. In women, this value was also lower than the observed in Ecuador $(91.5 \mathrm{~cm})(11)$ and Portugal $(89 \mathrm{~cm})^{23}$, similar than Brazil $(10)$, but higher than Japan $(80 \mathrm{~cm})^{24}$ and in eight countries of Sub-Sahara Africa $(81 \mathrm{~cm})^{25}$.

The prevalence of MetS in this report (47.6\%) was higher than that observed in previous studies, including populations from three regions of Venezuela between 2006 and $2010(35.7 \%)^{26}$, and higher than other reports presented in five countries in Central America at $30.3 \%{ }^{27}$, and the US at $34.7 \%{ }^{28}$. However, the comparison among these studies is very limited because many different definitions of MetS were used, the most frequently used was the Adult Treatment Panel III (ATPIII) criteria $^{29}$. The limitation of the ATPIII definition is that by relying on impaired fasting glucose, BMI, and waist circumference, alone, the proportion of subjects at risk including Stage 1 DBCD (insulin resistance and other forms of $A B C D$ with normal $B M I$ and WC, but abnormal adiposity distribution or function) and Stage 2 DBCD (prediabetes with impaired glucose tolerance) is underestimated. This limitation is compounded by biometric cutoffs (BMI, waist circumference, blood glucose, etc.) that may differ among the various ethnocultural populations in Latin American adults, which is a population that develops inflammation, insulin resistance, and CVD at lower levels of adiposity ${ }^{30}$. These variations were observed in a systematic review, including 12 studies in Latin America, where the prevalence of MetS ranged from $18.8 \%$ to $43.3 \%$, and the prevalence of each modifiable CVD risk component significantly varied among populations ${ }^{31}$. In comparison with Cacucasians, studies in Venezuelan population have described the presence of obesity (excess of adiposity) at lower cutoffs for BMI (27.5), insulin resistance at lower HOMA, MetS at lower epicardic fat, and metabolic abnormalities at lower WC ${ }^{12,14,32,33 .}$

Unhealthy eating patterns and physical inactivity are the main drivers of cardiometabolic alterations ${ }^{34}$. Hence, the high prevalence of cardiometabolic risk factors in Venezuela is not surprising, considering the stressful environment. An adverse lifestyle among inhabitants typically results from chronic social, political, and economic turmoil ${ }^{35}$. Chronic stress acts in the brain, increasing appetite, locomotor activity, and food-seeking behavior ${ }^{36}$. High glucocorticoid levels are related to unhealthy behaviors ${ }^{37}$. Glucocorticoids increase appetite, especially for foods rich in salt, trans fat, and high caloric content and are related to chronic fatigue, which leads to a sedentary lifestyle; additionally, endogenous glucocorticoids promote abdominal obesity, insulin resistance, salt retention, and immunosuppression ${ }^{38,39}$. Chronic stress also activates the sympathoadrenal and pituitary-adrenal axes increasing cardiac output and peripheral vascular resistance, which elevate blood pressure $^{40}$. The effects of stress on inflammation, T2D, obesity, and CVD are mediated by direct innervations of lymphatic tissue and complex effects on behaviors that affect dietary patterns and physical activity ${ }^{35}$. Interestingly, these changes appear despite parallel effects of a stressful environment generated by the widespread humanitarian crisis in Venezuela that reduces the access to calorically dense food (e.g., oils) and increase non-programmed physical activities (primarily due to the lack of public transportation).

The main limitation of this study is the cross-sectional design, impeding to determine causal relation, future prospective studies are mandatory to determine which WC cutoffs predict CVD events, T2D, and mortality. Different fat measurements, especially visceral fat by IMAGEN studies, are better predictors of cardiometabolic risk factors and were not measured in the present study; however, these measurements are complicated to implement and represent an elevated cost in daily practice. The strengths of this report include the national representativeness of EVESCAM, including subjects with 20 years or older from the eight regions of the country, the formal sampling method, and a unique setting influenced by extraordinary stress. Thus, the results of the current study could be generalized to the full adult population of Venezuela.

\section{Conclusion}

A WC cutoff value of $90 \mathrm{~cm}$ for men and $86 \mathrm{~cm}$ for women were related with higher sensitivity and specificity associated with $\geq 2$ cardiometabolic risk factors. Incorporating this new WC cutoff as part of the diagnostic criteria was found a high prevalence of abdominal obesity and MetS in the country. The specific drivers of cardiometabolic alterations in this unique population setting need to be evaluated but social determinants appear to be very important contributing factors.

\section{Funding}

The EVESCAM was partially funded by a grant of Novartis and donations. 


\section{Conflicts of Interest}

The authors declare no conflicts of interest.

\section{Ethical disclosures}

Protection of human and animal subjects. The authors declare that no experiments were performed on humans or animals for this study.

Confidentiality of data. The authors declare that they have followed the protocols of their work center on the publication of patient data.

Right to privacy and informed consent. The authors declare that no patient data appear in this article.

\section{References}

1. Institute for Health Metrics and Evaluation, Venezuela Profile; 2019 Available from: http://www.healthdata.org/venezuela. [Last accessed on Sep 2019].

2. WHO Expert Consultation. Appropriate body-mass index for Asian populations and its implications for policy and intervention strategies. Lancet. 2004;363:157-63

3. Mechanick JI, Hurley DL, Garvey WT. Adiposity-based chronic disease as a new diagnostic term: the American association of clinical endocrinologists and American college of endocrinology position statement. Endocr Pract. 2017;23:372-8.

4. Mechanick Jl, Garber AJ, Grunberger G, Handelsman Y, Garvey T. Dysglycemia-based chronic disease: an American association of clinical endocrinologists position statement. Endocr Pract. 2018;24:995-1011.

5. Batsis JA, Nieto-Martinez RE, Lopez-Jimenez F. Metabolic syndrome: from global epidemiology to individualized medicine. Clin Pharmacol Ther. 2007;82:509-24

6. Galassi A, Reynolds K, He J. Metabolic syndrome and risk of cardiovascular disease: a meta-analysis. Am J Med. 2006;119:812-9.

7. Dragsbæk K, Neergaard JS, Laursen JM, Hansen HB, Christiansen C, Beck-Nielsen $\mathrm{H}$, et al. Metabolic syndrome and subsequent risk of Type 2 diabetes and cardiovascular disease in elderly women: challenging the current definition. Medicine. 2016;95:e4806.

8. Esposito K, Chiodini P, Colao A, Lenzi A, Giugliano D. Metabolic syndrome and risk of cancer: a systematic review and meta-analysis. Diabetes Care. 2012;35:2402-11.

9. Alberti KG, Zimmet P, Shaw J. Metabolic syndrome-a new world-wide definition. A consensus statement from the international diabetes federation. Diabet Med. 2006;23:469-80.

10. Cardinal TR, Vigo A, Duncan BB, Matos SM, da Fonseca MJ, Barreto SM et al. Optimal cut-off points for waist circumference in the definition of metabolic syndrome in Brazilian adults: baseline analyses of the longitudinal study of adult health (ELSA-Brasil). Diabetol Metab Syndr. 2018;10:49.

11. Torres-Valdez M, Ortiz-Benavides R, Sigüenza-Cruz W, Ortiz-Benavides A, Añez R, Salazar J, et al. Punto de corte de circunferencia abdominal para el agrupamiento de factores de riesgo metabólico: una propuesta para la población adulta de Cuenca, Ecuador. Rev Argent Endocrinol Metab. 2016:53:59-66.

12. Bermudez V, Rojas J, Salazar J, Añez R, Chavez-Castillo M, Gonzalez R, et al. Optimal waist circumference cut-off point for multiple risk factor aggregation: results from the Maracaibo city metabolic syndrome prevalence study. Epidemiol Res Int. 2014;2014:718571.

13. Villalobos E, Mata K, Guerrero Y, Añez R, Rojas J, Bermúdez V. Determinación del Punto de Corte Óptimo Para la Circunferencia Abdomina Mediante su Agregación con Múltiples Factores de Riesgo: una Propuesta Para la Población Adulta de San Cristóbal, Estado Táchira; 2016.

14. Aschner P, Buendía R, Brajkovich I, Gonzalez A, Figueredo R, Juarez XE et al. Determination of the cutoff point for waist circumference that establishes the presence of abdominal obesity in Latin American men and women. Diabetes Res Clin Pract. 2011;93:243-7.

15. Selvaraj S, Martinez EE, Aguilar FG, Kim KY, Peng J, Sha J, et al. Association of central adiposity with adverse cardiac mechanics: findings from the hypertension genetic epidemiology network study. Circ Cardiovasc Imaging. 2016;9(6):10.1161/CIRCIMAGING.115.004396 e004396.
16. Nieto-Martínez R, Marulanda MI, Ugel E, Duran M, González-Rivas J, Patiño M, et al. Venezuelan study of cardio-metabolic health (EVESCAM): general description and sampling. Med Interna. 2015;31:102-11.

17. Nieto-Martínez R, Marulanda MI, González-Rivas JP, Ugel E, Durán M, Barengo N, et al. Cardio-metabolic health Venezuelan study (EVESCAM): design and implementation. Invest Clin. 2017;58:56-61.

18. Nieto-Martínez R, González JP, Lima-Martínez M, Stepenka V Rísquez A, Mechanick JI. Diabetes care in Venezuela. Ann Glob Health. 2015;81:776-91.

19. von Elm E, Altman DG, Egger M, Pocock SJ, Gotzsche PC, Vandenbroucke JP. The strengthening the reporting of observational studies in epidemiology (STROBE) statement: guidelines for reporting observational studies. PLoS Med. 2007;4:e296.

20. Vera-Cala LM, Orostegui M, Valencia-Angel LI, Lopez N, Bautista LE. Accuracy of the Omron HEM-705 CP for blood pressure measurement in large epidemiologic studies. Arq Bras Cardiol. 2011;96:393-8.

21. Alberti KG, Eckel RH, Grundy SM, Zimmet PZ, Cleeman JI, Donato KA, et al. Harmonizing the metabolic syndrome: a joint interim statement of the international diabetes federation task force on epidemiology and prevention; national heart, lung, and blood institute; American heart association; world heart federation; international atherosclerosis society; and international association for the study of obesity. Circulation. 2009;120:1640-5.

22. Méndez-Castellano H, Méndez MC. Estratificación social y humana. Método de graffar modificado. Arch Venez Pueric Pediatr. 1986;49:93-104.

23. Raposo L, Severo M, Santos AC. Adiposity cut-off points for cardiovascular disease and diabetes risk in the Portuguese population: the PORMETS study. PLoS One. 2018:13:e0191641.

24. Hu H, Kurotani K, Sasaki N, Murakami T, Shimizu C, Shimizu M, et al. Optimal waist circumference cut-off points and ability of different metabolic syndrome criteria for predicting diabetes in Japanese men and women: Japan epidemiology collaboration on occupational health study. BMC Public Health. 2016;16:220.

25. Ekoru K, Murphy GA, Young EH, Delisle H, Jerome CS, Assah F, et al. Deriving an optimal threshold of waist circumference for detecting cardiometabolic risk in sub-Saharan Africa. Int J Obes (Lond). 2017;42: 487-94.

26. Brajkovich I, González-Rivas J, Ugel E, Rísquez A, Nieto-Martínez R Prevalence of metabolic syndrome in three regions in Venezuela: the VEMSOLS study. Int J Cardiovasc Sci. 2018;31:603-9.

27. Wong-McClure RA, Gregg EW, Barcelo A, Lee K, Abarca-Gomez L, Sanabria-Lopez $\mathrm{L}$, et al. Prevalence of metabolic syndrome in Central America: a cross-sectional population-based study. Rev Panam Salud Publica. 2015;38:202-8.

28. Aguilar M, Bhuket T, Torres S, Liu B, Wong RJ. Prevalence of the metabolic syndrome in the United States, 2003-2012. JAMA. 2015;313:1973-4

29. National Cholesterol Education Program (NCEP) Expert Panel on Detection, Evaluation, and Treatment of High Blood Cholesterol in Adults (Adult Treatment Panel III). Third report of the national cholesterol education program (NCEP) expert panel on detection, evaluation, and treatment of high blood cholesterol in adults (adult treatment panel III) final report. Circulation. 2002:106:3143-421.

30. Lopez-Jaramillo P, Lahera V, Lopez-Lopez J. Epidemic of cardiometabolic diseases: a Latin American point of view. Ther Adv Cardiovasc Dis. 2011;5:119-31.

31. Marquez-Sandoval F, Macedo-Ojeda G, Viramontes-Horner D, Ballart JD, Salvado JS, Vizmanos B. The prevalence of metabolic syndrome in Latin America: a systematic review. Public Health Nutr. 2011;14:1702-13.

32. Bermudez V, Rojas J, Martinez MS, Apruzzese V, Chavez-Castillo M, Gonzalez R, et al. Epidemiologic behavior and estimation of an optimal cut-off point for homeostasis model assessment-2 insulin resistance: a report from a Venezuelan population. Int Sch Res Notices. 2014;2014:616271.

33. Lima-Martinez MM, Blandenier C, lacobellis G. Epicardial adipose tissue: more than a simple fat deposit? Endocrinol Nutr. 2013;60:320-8.

34. González-Rivas J, Molina T. Síndrome metabólico. Med Interna. 2011; 27:156-63.

35. Lewington S, Clarke R, Qizilbash N, Peto R, Collins R. Age-specific relevance of usual blood pressure to vascular mortality: a meta-analysis of individual data for one million adults in 61 prospective studies. Lancet. 2002;360:1903-13

36. McEwen BS, Wingfield JC. The concept of allostasis in biology and biomedicine. Horm Behav. 2003;43:2-15.

37. Yau YH, Potenza MN. Stress and eating behaviors. Minerva Endocrinol. 2013;38:255-67.

38. Kelly SJ, Ismail M. Stress and Type 2 diabetes: a review of how stress contributes to the development of Type 2 diabetes. Annu Rev Public Health. 2015;36:441-62.

39. Yau YH, Potenza MN. Stress and eating behaviors. Minerva Endocrinol. 2013;38:255-67.

40. Tsigos C, Kyrou I, Kassi E, Chrousos GP. Stress, endocrine physiology and pathophysiology. In: de Groot LJ, Chrousos G, Dungan K, Feingold KR, Grossman A, Hershman JM, et al., editors. Endotext. South Dartmouth, MA: MDText.Com, Inc.; 2000. 